\title{
Keynote: \\ Why Would Vodafone Focus on Sustainability?
}

\author{
Chris Burgess \\ Vodafone Group \\ Chris.Burgess@vodafone.com
}

\begin{abstract}
Vodafone is a large successful company focused on delivering value to customers and returns to shareholders. Why would a company, any company, want to divert their attention onto sustainability, particularly in a recession?

This presentation will focus on the corporate business case for sustainability, looking at social, economic and environmental elements. It will discuss the return on investment and why mobile telecoms companies are in a privileged position in regards to the sustainability agenda.
\end{abstract}

As well as looking at strategy, the presentation will examine how sustainability is operationalised within the business.

\section{BIOGRAPHY}

Chris Burgess is the Corporate Responsibility Director for Vodafone Group and has responsibility for Group-wide CR strategy development, external engagement and reporting, input to policy formation and social and low carbon applications of mobile technology.

Chris joined Vodafone in 2002 and was responsible for putting in place many of the core systems, processes and metrics that now underpin Vodafone's approach to CR. He became Director in November 2007.

Prior to joining Vodafone, Chris had many years working as a consultant on sustainability issues and led Deloitte's UK consulting business in this field. Many years ago he was a qualified Chartered Accountant. Chris has an Hons Degree in Zoology from Bristol University. 